\title{
Performance of un-reinforced burned clay brick masonry walls retrofitted with locally available materials
}

\author{
W.S. Wasundara Mendis, G.S.Y. De Silva* and G.H.M.J. Subashi De Silva \\ Department of Civil and Environmental Engineering, Faculty of Engineering, University of Ruhuna, Galle.
}

Submitted: 11 December 2017; Revised: 26 July 2018; Accepted: 17 August 2018

\begin{abstract}
In Sri Lanka, there is a large number of unreinforced masonry buildings and they have possessed a deepseated view in local culture since ancient time. Un-reinforced masonry is the most vulnerable against earthquakes, which highlights the need of introducing proper techniques for retrofitting of existing un-reinforced masonry buildings. The objective of this study is to evaluate the possibility of selected techniques (external poly propylene band mesh, ferrocement belts and the proposed external bamboo strip mesh) to increase seismic safety of existing masonry structures. Masonry walls having the size of $600 \mathrm{~mm} \times 600 \mathrm{~mm} \times 215 \mathrm{~mm}$ were cast using bricks. The masonry walls with and without retrofitting were tested under static diagonal compression test. The effectiveness of retrofitting techniques was evaluated using initial cracking load, ultimate load carrying capacity, crack initiation and propagation, residual strength and failure mode, shear stress and wall stiffness. Test results indicated that retrofitting of un-reinforced masonry walls with bamboo strip mesh and poly propylene band mesh could be effective and reliable strengthening techniques. These methods are also economical and simple in technique. The wall retrofitted with ferrocement belts collapsed without catastrophic failure. Withal, this technique was capable of dissipating some energy and redistributing the load, and showed considerable visible signs before the collapse. The ferrocement belts method might be reliable for retrofitting of un-reinforced masonry buildings.
\end{abstract}

Keywords: Diagonal shear test, in-plane load, retrofitting, seismic resistant, un-reinforced brick masonry.

\section{INTRODUCTION}

Sri Lankan architecture is mainly based on masonry from long ago. Among different types of masonry, unreinforced masonry (URM) construction has possessed the local culture of Sri Lanka especially in residential building construction since ancient time. One of the most significant reasons for the popularity of such construction is that Sri Lanka has been considered as an earthquake free zone. Other reasons are great attributes possessed by URM constructions: URM is a low-cost, readily available construction material manufactured by local communities. In addition, masonry construction has several other desirable features such as durability, less labour intensity, ease of construction and alteration after construction, eco-friendliness, heat and sound insulation, fire resistance and better architectural character. Unfortunately, URM buildings are the most vulnerable in the face of earthquakes (Blondet et al., 2003; Bartolome et al., 2004; 2008), since it is made of a heavy and brittle material with low tensile strength and exhibits little ductility when subjected to seismic effects. Considerable damage and loss of life has occurred due to earth tremors in areas where URM constructions were used in Sri Lanka (Kodippili, 2009; Uduweriya et al., 2013) and many other countries (Mendis et al., 2012).

\footnotetext{
*Corresponding author (sudhira@cee.ruh.ac.lk; (iD https://orcid.org/0000-0003-0804-5097)
} 
Further, the location of Sri Lanka on the earth is getting more vulnerable to unpredicted large earthquakes (Dissanayake \& Mohadewan, 2004; Munasinghe \& Curray, 2013). Hence, necessary precautions need to be taken regarding the existing URM buildings in Sri Lanka to avoid and control catastrophic situations that may happen in the future.

In this regard, retrofitting of existing URM buildings may emerge as a possibility, which implies incorporation of earthquake resistant measures to existing URM buildings in terms of strength and ductility (Mendis et al., 2014a). Retrofitting is a difficult task because of the great number of seismically deficient buildings, but it is essential due to economic considerations.

During large earthquakes, URM walls may be subjected to two most common modes of masonry failures: out-of-plane and in-plane failures, as well as failures from vertical compression due to self-weight and overburden loads, with in-plane loading governing the global strength and stiffness of the building. Accordingly, the introduced retrofitting technique should be tested for dynamic loading as well as static loading, on both inplane and out-of-plane behaviour of masonry buildings. Further, the retrofitting technique must have the ability to increase both load bearing and deformation capacity of walls.

Various conventional and non-conventional rehabilitation and retrofitting techniques are available worldwide to enhance the seismic performance of URM buildings (Mendis et al., 2014b). A considerable amount of research has been carried out throughout the world on retrofitting of URM using these techniques in the past two decades (Mendis et al., 2014b). These well-established techniques have not been studied for indigenous materials and building systems commonly used in Sri Lanka. Some of the retrofitting methods are expensive and require high level of technology while some materials for some retrofitting techniques cannot be found easily from the rural areas of developing countries like Sri Lanka. Therefore, it is highly needed to introduce low cost retrofitting methods with simple technology and with materials available within rural areas. Hence, the objectives of this study were to introduce suitable seismic resistant techniques using locally available materials: bamboo strips, poly propylene (PP) bands and ferrocement belts against static in-plane shear load and to evaluate the safety of the proposed retrofitting techniques against earthquakes.

Effectiveness of a retrofitting technique and the materials used for retrofitting can be estimated significantly by quantitative and qualitative performances of the walls. Quantitative performance can be estimated using parameters such as, initial cracking load, load bearing capacity, shear stress, deformation capacity and stiffness before and after initial cracking, whereas qualitative performance can be evaluated using final failure of the wall, crack propagation over the wall and diagonal force $v s$ vertical displacement curve. The behaviour of retrofitted walls would be idealised as shown in Figure 1, for illustrating the method of calculating the stiffness of the specimen.

Stiffness is defined as the gradient of the diagonal force $(P)$ - vertical displacement $(D)$ curve. The initial stiffness $\left(K_{o}\right)$ is derived from the ratio between the variation of diagonal force at two stages and variation of corresponding vertical displacements just before the initial cracking of the wall (Sathiparan et al., 2008).

$K_{o}=\frac{P_{o}-0}{D_{o}-0} \rightarrow K_{o}=\frac{P_{o}}{D_{o}}$

where, $P_{o}$ is the initial cracking load and $D_{o}$ is the corresponding vertical displacement. The residual stiffness $\left(K_{r}\right)$ can be calculated from the ratio between the variation of diagonal force at two stages after the initial cracking and the variation of corresponding vertical displacements (Sathiparan et al., 2008).

$K_{r}=\frac{P_{\max }-P_{r}}{D_{\max }-D_{r}}$

where, $P_{\max }$ is the maximum load of the wall, $\mathrm{P}_{\mathrm{r}}$ is the residual strength after initial cracking of the wall and $D_{\max }$ and $\mathrm{D}_{\mathrm{r}}$ are the corresponding displacements for $P_{\max }$ and $P_{r}$, respectively. The average shear stress $(\boldsymbol{\tau})$ is obtained from the experimentally measured diagonal force $P$ (ASTM E519/E519M, 2010);

$\tau=\frac{0.707 P}{0.5 t(L+H)}$

where $t$ is the wall thickness and $L$ and $H$ are the length and height of the wall, respectively. The increment of maximum load bearing capacity possessed by a retrofitted wall compared to the traditional URM wall, which is not retrofitted can be expressed as;

Load increment $=$

$$
\left(\frac{P_{\max (\text { retrofitted wall })}-P_{\max (\text { control wall })}}{P_{\max (\text { control wall })}}\right) * 100 \%
$$


Where, $P_{\max (\text { retrofitted wall) }}$ and $P_{\max \text { (control) }}$ are the maximum diagonal forces for retrofitted wall and for the control wall (non-retrofitted wall), respectively.

\section{METHODOLOGY}

Four URM walls were cast to evaluate the performance of URM walls with and without retrofitting. Both sides of all the test walls used to retrofit were symmetrically strengthened using relevant materials. Three techniques: bamboo strip mesh, poly propylene (PP) band mesh and ferrocement belts were evaluated as retrofitting methods. One specimen was treated as the control wall panel (i.e., NRW - non-retrofitted unreinforced masonry wall) and the other specimens were used for each retrofitting technique: bamboo strip mesh (i.e., RBS - retrofitted masonry wall with bamboo strip mesh), PP-band mesh (i.e., RPP - retrofitted masonry wall with PP-band mesh) and ferrocement belts (i.e., RFB - retrofitted masonry wall with ferrocement belts). The performances were evaluated using parameters such as deformation, ultimate load carrying capacity, load at initial crack formation, stiffness, shear stress, crack propagation and failure modes of the wall. The experimental parameters of each wall unit are summarised in Table 1.

Table 1: Proposed retrofitting techniques for URM dwellings

\begin{tabular}{ll}
\hline Specimen & Retrofitting technique \\
\hline NRW & Control unit - no retrofit \\
RBS & $\begin{array}{l}20 \mathrm{~mm} \text { wide and } 5 \mathrm{~mm} \text { thick horizontal and vertical } \\
\text { bamboo strips }\end{array}$ \\
RPP & $\begin{array}{l}10 \mathrm{~mm} \text { wide horizontal and vertical PP-bands } \\
\text { RFB }\end{array}$ \\
\end{tabular}

NRW - non-retrofitted unreinforced masonry wall; RBS - retrofitted masonry wall with bamboo strip mesh; RPP - retrofitted masonry wall with PP-band mesh; RFB - retrofitted masonry wall with ferrocement belts

\section{Masonry walls - test specimens}

Burned solid clay bricks (size of a brick: $215 \times 102.5 \times$ $65 \mathrm{~mm}$ ) were used to build the test walls. The proposed retrofitting systems aim to improve the performance of walls by increasing the shear strength above the flexural strength and by increasing the ductility and energy dissipation capability. Walls with aspect ratio (height/ length) less than 1.0 have flexural strengths higher than their shear strength and these walls should fail in shear in a non-ductile manner (Taghdi et al., 2000a, b). Therefore, all specimens were chosen with an aspect ratio of 1.0 to ensure that most of the URM walls would exhibit shear induced damages and in-plane failure would be dominated. The test walls were constructed in double wythe with the size of $600 \times 600 \times 215 \mathrm{~mm}$ as shown in Figure 1 .

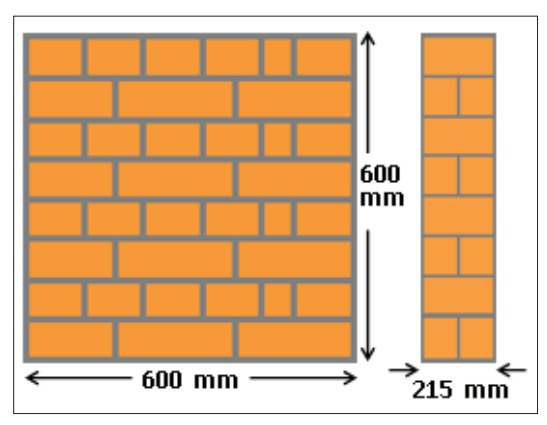

Figure 1: The configuration of test wall

Mortar joint thickness was $10 \mathrm{~mm}$ and the 1:6 cementsand mortar (in volume basis) was used. A certain number of holes were made at designed suitable spacing only in one wall which would be retrofitted with the bamboo strip mesh. These holes were used to insert galvanised steel binding wires to connect the bamboo strip mesh to the wall. The walls were cured with water spray for $28 \mathrm{~d}$ to achieve maximum strength. At the end of the curing process, retrofitting was conducted.

\section{Retrofitting procedure}

Three URM walls, were retrofitted symmetrically using bamboo strip mesh, PP-band mesh and ferrocement belts, separately where one wall was used to retrofit with each technique.

\section{Poly propylene band mesh}

One masonry wall was tightly and fully wrapped using PP-bands having a width of $10 \mathrm{~mm}$ as shown in

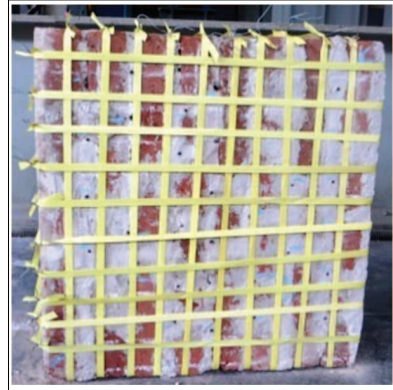

(a)

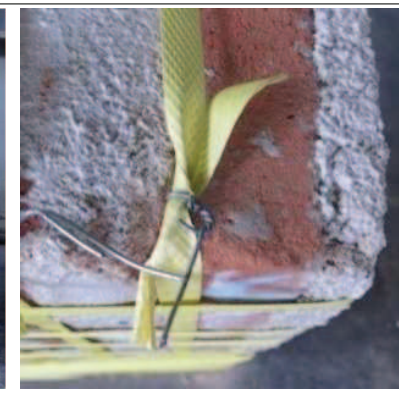

(b)
Figure 2: $\quad$ PP-band mesh technique (RPP): (a) fully retrofitted wall; (b) connecting the end of a PP-band strip 
Figure 2(a). End of each PP-band was connected using galvanised steel wires as illustrated in Figure 2(b). The parallel band spacing was kept as $50 \mathrm{~mm}$.

\section{Ferrocement belts}

Plain wave and electro galvanized steel wire mesh (SWM) with pitch of $2 \mathrm{~mm}$ and $0.5 \mathrm{~mm}$ diameter steel wires were used in ferrocement belt technique. Only one layer of steel mesh was used. The masonry wall was partially wrapped with two $1650 \mathrm{~mm}$ long and $150 \mathrm{~mm}$ wide meshes [Figure 3(a)] and each end of the mesh was connected with binding wires as shown in Figure 3(c). The meshes were also connected to the wall using bolts [Figure 3(a)]. Afterwards, only the areas covered by both meshes were plastered with $1: 3$ cementsand mortar [Figure 3(b)]. The sand used in mortar for plastering the wall was sieved by using a riddle of $3 \mathrm{~mm}$ mesh pitch to ensure effective bond between the wall and the SWM.

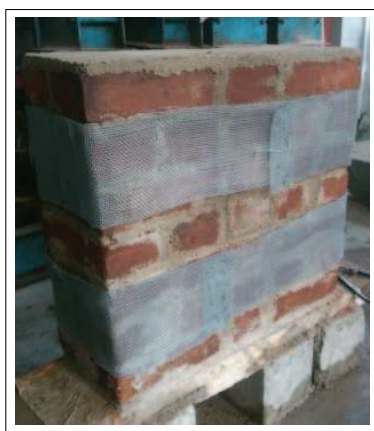

(a)

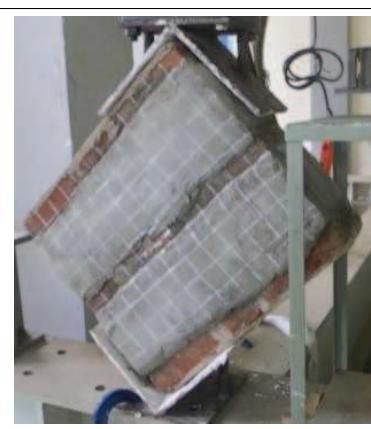

(b)

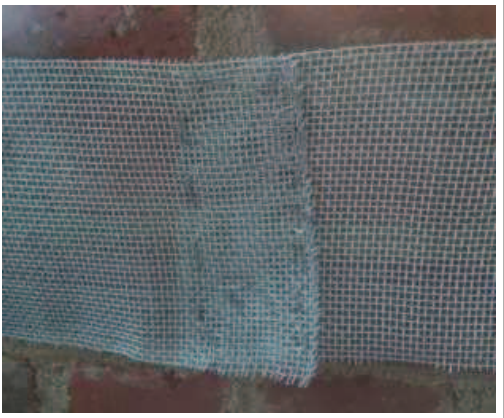

(c)

Figure 3: Ferrocement belts technique (RFB): (a) wrapping wall with SWM; (b) partially retrofitted wall; (c) binding each end of mesh

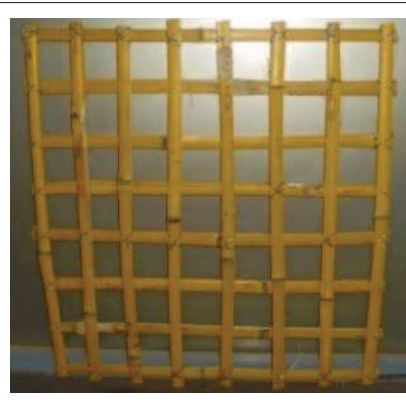

(a)

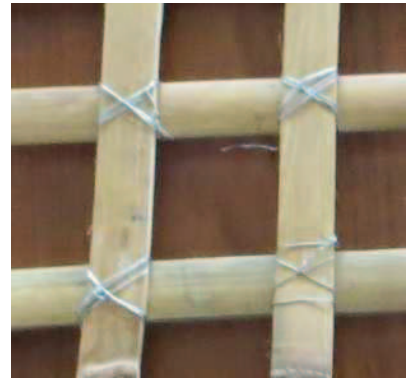

(b)

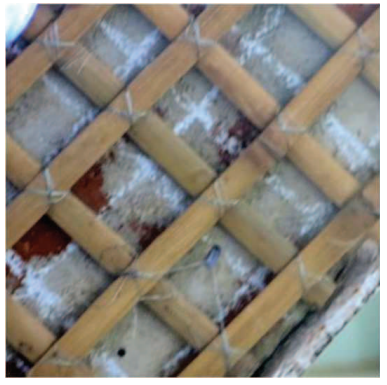

(c)

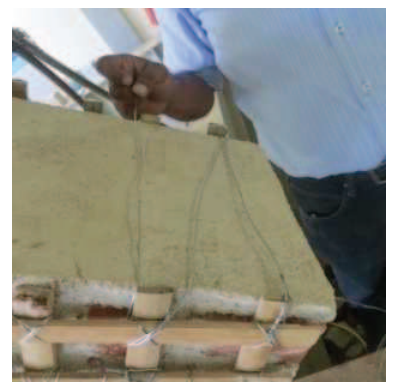

(d)

Figure 4: Bamboo strip mesh method (RBS): (a) bamboo mesh; (b) binding cross points of mesh; (c) connecting mesh on the wall; (d) connecting two meshes with each other

\section{Newly proposed method: bamboo strip mesh reinforcement}

Two bamboo strip meshes were prepared to retrofit the URM wall with holes (as described previously). Five millimeters thick and $20 \mathrm{~mm}$ wide 16 yellow bamboo strips were arranged in a mesh pattern with a pitch of $50 \mathrm{~mm}$ to prepare the mesh as shown in Figure 4(a). Each cross point of the mesh was tightly connected using galvanised steel binding wires [Figure 4(b)].
The masonry wall was symmetrically retrofitted with two meshes as one mesh on each wall surface $(600 \times 600 \mathrm{~mm})$ using binding wires inserted through holes in the wall as shown in Figure 4(c). Afterwards, the two meshes were connected with each other [Figure 4(d)] at four wall surfaces of $600 \times 215 \mathrm{~mm}$ with binding wires. The two meshes were connected to each other for the purpose of giving the effect of foundation, roof and supporting walls at bottom level, top level and left and right sides of the wall, respectively. The resulting structure was an 
integrated matrix, with a strong connection between the wall and the mesh.

\section{Experimental test setup}

Figure 5 shows the experimental test setup used in the laboratory to determine the shear failure of masonry walls and to evaluate the effectiveness of the proposed retrofitting methods against in-plane static loads. Diagonal compression test, which is available to investigate the in-plane diagonal shear strength of masonry walls was conducted on test specimens and ASTM E-519-02 standard guidelines were used in the test setup. The test wall was established and settled between two pairs of steel angle plates at the top and bottom as illustrated in Figure 5. The pair of steel angle plates consisted of two steel plates of $90^{\circ}$ degrees connected to a square shaped support. Both steel angle plates were created with an angle of $45^{\circ}$ degrees to the connected surface of the diagonally placed wall panel at the top and bottom as shown in Figure 5(b). The square shaped support was used to bolt the steel angle plates to the actuator and to the loading frame.

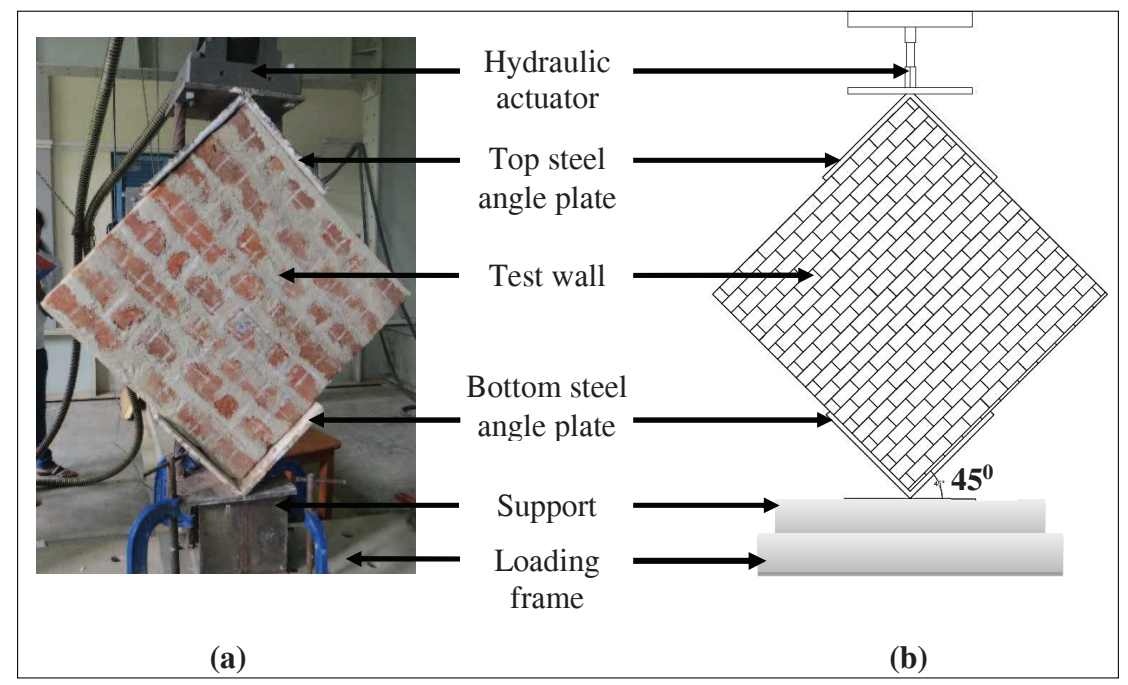

Figure 5: The test setup: (a) control wall in the test setup; (b) schematic diagram of the test setup

A $5 \mathrm{~mm}$ thick plaster of paris layer was applied on both steel plates at the interface between the test wall and the steel plate. This layer is crucial to carry out a better load transformation from the steel plate to the test wall. One of the steel angle plates was bolted to the hydraulic actuator and the other plate was placed on a support attached to the loading frame just below the actuator as shown in Figure 5. The specimen was carefully installed into the loading frame and checked for vertical alignment using a plumb bob.

Load was applied on the test walls along the vertical diagonal of the wall using the server controlled hydraulic actuator at a rate of approximately $0.1 \mathrm{mms}^{-1}$ under the displacement controlled method. A test wall was loaded till the wall unable to transfer the given load within the wall itself (i.e., the final failure of the wall). The applied diagonal force on the walls and the corresponding displacements (i.e., vertical shortening) along the loaded diagonal of the walls were recorded over time. Crack initiation and propagation and failure pattern of the walls were also observed.

\section{RESULTS AND DISCUSSION}

The effectiveness of three techniques: bamboo strip mesh, PP-band mesh and ferrocement belts for retrofitting URM shear walls against diagonal compression loading is evaluated in this section. Accordingly, static in-plane behaviour of retrofitted URM walls were compared and discussed using the parameters, vertical displacement, load carrying capacity, crack formation and propagation, and failure pattern. Test results for conventional URM wall (NRW) and URM walls retrofitted with bamboo strip mesh (RBS), PP-band mesh (RPP) and ferrocement belts (RFB) are shown in Table 2.

Figure 6 illustrates the diagonal compressive force variation with vertical deformation for all the test wall panels. 


\section{Non-retrofitted wall}

Figure 7(a) illustrates the crack patterns observed in the traditional URM wall (NRW-control specimen) just before it collapses. Only a few major cracks concentrated to a specific area were observed. Crack initiation in the NRW was observed in mortar joints, and the cracks developed and propagated along the mortar joints. Diagonal shear cracking is the most common masonry failure mode under seismic loads and it is generated for a combination of vertical compressions and in-plane horizontal loads. The principal tensile stresses developed in the wall due to this action exceed the tensile strength of masonry.

Table 2: Test results for control wall and retrofitted walls

\begin{tabular}{lcccc}
\hline Specimen & NRW & RBS & RPP & RFB \\
\hline Initial cracking load $(\mathrm{kN})$ & 26.70 & 32.69 & 24.95 & 28.60 \\
Peak load $-\mathrm{P}_{\max }(\mathrm{kN})$ & 26.70 & 43.83 & 30.94 & 44.60 \\
Peak load increment $(\%)$ & - & $64.16^{*}$ & $15.87^{*}$ & $67.04^{*}$ \\
Deflection at peak load $-\delta_{\mathrm{p}}(\mathrm{mm})$ & 05.30 & 25.34 & 12.29 & 09.86 \\
Maximum deflection $-\delta_{\max }(\mathrm{mm})$ & 06.33 & 27.99 & 25.34 & 24.72 \\
Initial stiffness $-\mathrm{K}_{\mathrm{o}}(\mathrm{kN} / \mathrm{mm})$ & 05.26 & 03.45 & 03.31 & 05.71 \\
Residual stiffness $-\mathrm{K}_{\mathrm{r}}(\mathrm{kN} / \mathrm{mm})$ & 0 & 00.74 & 01.54 & 03.66 \\
Shear stress $-\tau\left(\mathrm{N} / \mathrm{mm}^{2}\right)$ & 00.15 & 00.24 & 00.17 & 00.24 \\
Behaviour at test end & $\mathrm{C}$ & $\mathrm{NC}$ & $\mathrm{NC}$ & $\mathrm{C}$ \\
Failure mode & SH and SL with & $\mathrm{SH}, \mathrm{SL}$ & $\mathrm{SH}, \mathrm{SL}$ & $\mathrm{SH}, \mathrm{SL}$ \\
& Catastrophic failure & $\mathrm{NC}$ & $\mathrm{NC}$ & $\mathrm{C}, \mathrm{NCF}$ \\
\hline
\end{tabular}

* Peak load increment is presented compared to NRW

$\mathrm{C}$ - collapse; NCF - not a catastrophic failure; NC - not collapse; $\mathrm{SH}$ - shear mode of failure; $\mathrm{SL}$ - sliding mode of failure.

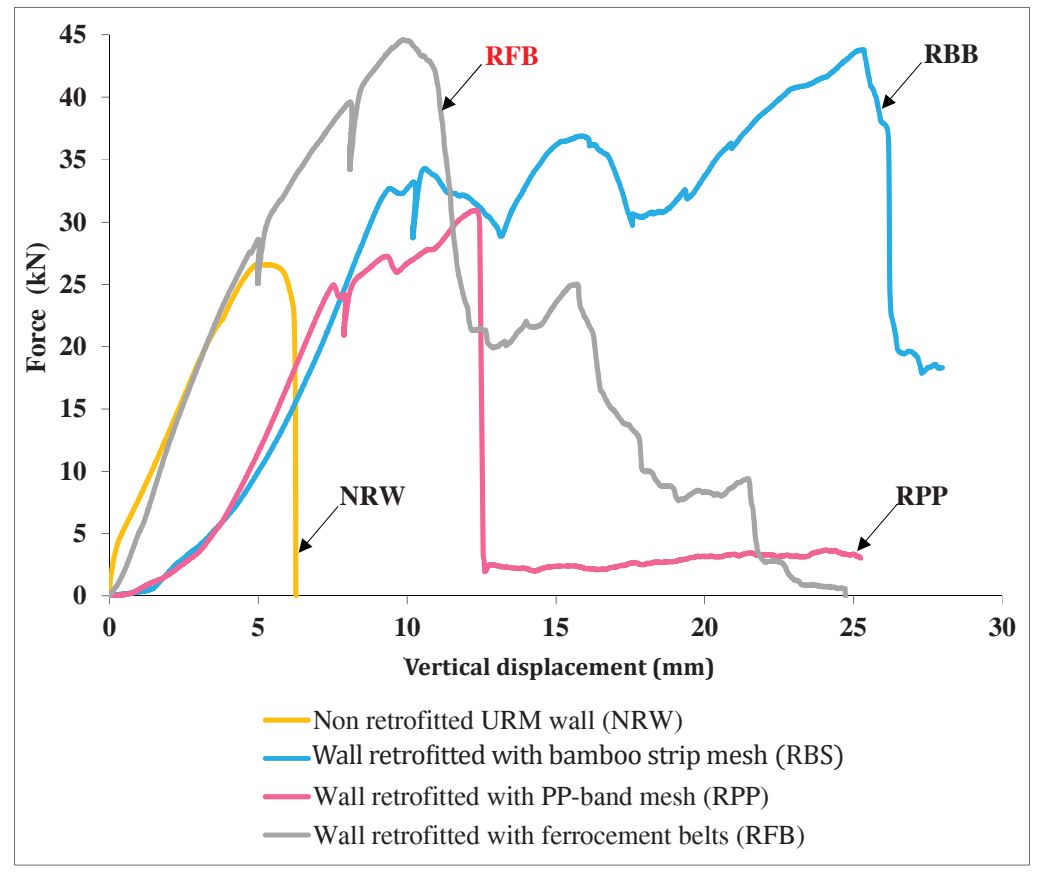

Figure 6: Load $v s$ vertical deformation for test walls 
The bricks have not been damaged at failure of the wall but have been separated due to the failure of mortar joints leading to collapsing of the wall. This is attributed to the weak mortar joint bond strength compared to the tensile strength of the burned clay bricks. The wall exhibited an approximately linear behaviour up to first visible cracking (Figure 6). Afterwards, cracks were visible along the middlemost bed joint ( $5^{\text {th }}$ bed joint) causing sliding of the upper part of the wall which is generally called shear sliding. The observed shear slip failure mode was catastrophic [Figure 7(b)] and occurred without much time elapse between crack initiation at the block mortar interface and the consequential debonding of blocks. The assemblage split mainly into two parts and subsequently disintegrated along a diagonal stepped joint and bed joint. Just before the attainment of maximum diagonal force, 2 - 3 lengthy diagonal cracks developed [Figure 7(a)]. Brittle failure was observed just after the wall gained the ultimate load as illustrated by Figure 7(b). The wall failed at a very low diagonal force [just below $27 \mathrm{kN}$ (Table 2)] and vertical displacement [just above $6 \mathrm{~mm}$ (Table 2)]. This is a result of the weak mortar joint bond strength and the absence of friction resistance due to lack of compressive stress, which is normal to the mortar bed joints.

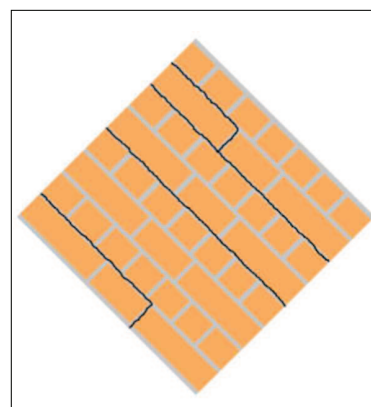

(a)

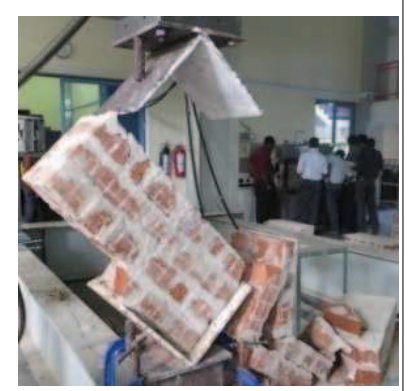

(b)
Figure 7: Specimen NRW: (a) crack formation; (b) specimen at the failure

\section{Wall retrofitted with bamboo strip mesh}

Beginning of failure occurred in the form of diagonal shear cracking, which spread through one third and two thirds of the horizontal diagonal of the wall. The diagonal cracks developed into major cracks at a later stage and heavy local crushing was observed near the supporting shoe, whereas both edges of the horizontal diagonal were undamaged. It could be observed that the propagation of cracks were in a wider area on the wall [Figure 8(a)] than that of NRW, wall RPP and wall RFB. The cracks propagated smoothly from top to bottom along the loaded diagonal axis of the wall RBS instead of a few major cracks concentrating along the mortar bedding lines in the NRW [Figure 7(a)]. Moreover, the wall RBS showed cracks which were larger in number, shorter in length and smaller in crack width, and propagated over a wider area [Figure 8(a)] than those in the wall RPP [Figure 9(a)]. The bamboo strip mesh significantly affected the first visible cracking load of the masonry wall [32.69 kN (Table 2)]. The compressive strength and stiffness of bamboo strips together possess a certain degree of load bearing capacity.

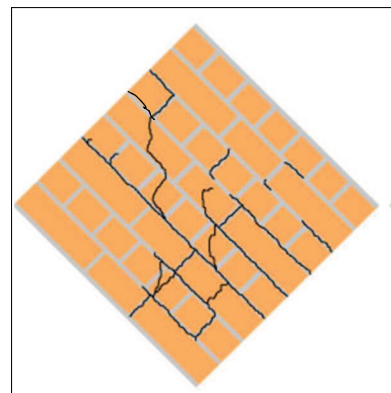

(a)

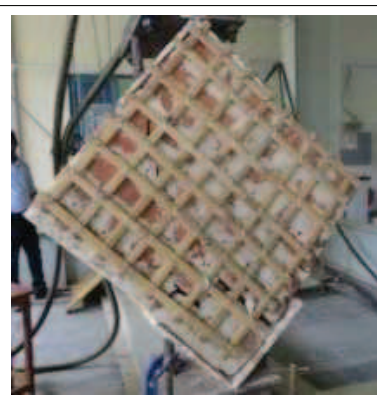

(b)
Figure 8: Specimens RBS: (a) crack formation; (b) specimen at the failure

The initial cracking of the wall RBS was followed by a sharp drop of the remaining strength capacity by $68.95 \%$ out of its maximum peak strength of $44 \mathrm{kN}$ and which was greater than that of the wall RPP. Thereafter, subsequent strength drops were quickly regained (Figure 6) due to the elastic behaviour of bamboo strips and the mesh formation. The bamboo strip mesh allowed the wall to gain the highest deformation capacity where vertical shortening along the loaded diagonal was just below $28 \mathrm{~mm}$. The wall possessed a residual stiffness of $0.74 \mathrm{kN}$ until it reached its maximum load bearing capacity. Then, the residual strength dropped drastically to the lowest load $(17.87 \mathrm{kN})$ gained by the wall after its first crack initiation, which was significantly higher compared to which was gained by the wall RPP $(1.95 \mathrm{kN})$ (Figure 6). Subsequently, the wall reached its final failure as a combination of sliding shear and diagonal tension as shown by Figures 8(a) and (b). At the end of the test, although almost all the walls RBS showed stepped-joint and bed-joint sliding, the wall did not lose its stability and did not collapse [8(b)]. No tensile failure in bamboo strips was observed, but buckling of bamboo strips occurred due to compression of strips. 
The main effect of the bamboo strip mesh is restraining the separated masonry fragments for allowing the redistribution of the load within the masonry itself. This was attributed by the formation of further cracks upon continuous loading (Figure 6). Vertical strips bare compression load once sliding of rows [Figure 8(b)], resulted in increasing the masonry wall frictional resistance to shear sliding. Through friction, energy from alien stresses dissipated. Vertical strips also redistributed the load, eliminating the concentration of load at the same masonry course, but allowing the deformation of the wall panel. Horizontal strips directly bear the load by resisting the separation of bricks within the same row allowing vertical strips to keep redistribution of the load over a long period while preventing or delaying the loss of debris. Both types of strips together improve the ductility with a rigid box-like enclosure resulting in preventing the collapse of damaged masonry walls on occupants and nearby buildings.

The wall RBS also kept the residual strength in a significant pattern compared to the wall RPP (Figure 6) by regaining the lost strength until the end of the test. It revealed that the bamboo strip mesh helps the masonry wall to redistribute and dissipate energy more effectively, compared to the PP-band mesh technique. Further, bamboo strips limited the shear sliding of the upper part of the wall up to about $10 \mathrm{~mm}$ (Table 2) while the PP-band mesh allowed the wall to slide to nearly 22 $\mathrm{mm}$ (Table 2) which is twice larger than that of the wall RBS. Bamboo strips have a higher tensile strength and compressive strength compared to those of PP-bands. Consequently, bamboo strips give higher frictional resistance against shear sliding and higher resistance against separation of bricks within the same brick course of the wall [Figure 8(b)] than those given by vertical PPbands and horizontal PP-bands, respectively.

\section{Wall retrofitted with PP-band mesh}

Failure initiated in the form of diagonal cracks which were distributed within the middle one third and two thirds of horizontal diagonal of the wall. Propagation of cracks was in a wider area in the wall with PP-band mesh (RPP) [Figure 9(a)] than that of the conventional URM wall (NRW). The cracks propagated from top to bottom of the wall along the loaded diagonal which was an effective improvement in wall behaviour than a few major cracks propagated through a specific area on the NRW [Figure 7(a)]. The influence of PP-band mesh could not be observed before the first crack, where an increase of peak strength of the wall RPP could be seen only after initiation of the first crack (Figure 9). The reason for this phenomena is that PP-bands have a relatively

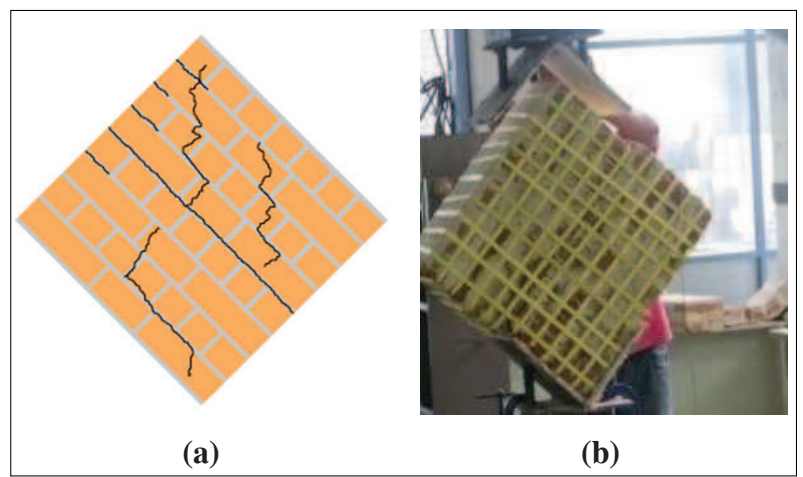

Figure 9: Specimens RPP: (a) crack formation; (b) specimen at the failure

low stiffness compared to masonry walls (Mendis et al., 2014b).

The initial cracking in the wall was followed by a sharp drop of the remaining strength capacity by $77.35 \%$ out of its maximum peak strength of $31 \mathrm{kN}$ (Table 2). Afterwards, the wall started to restrain the separation of wall fragments due to the elastic behaviour of PP-bands and the arrangement of mesh resulted in regaining the subsequent strength drop of the wall (Figure 6). The PP-band mesh allowed the given external force to be redistributed throughout the mesh and masonry wall, which was shown by the formation of further cracks developed in the wall upon continued loading (Figure 6). After the first crack initiation, the wall kept a residual stiffness of $1.54 \mathrm{~N} / \mathrm{m}^{2}$ until it reached its final failure. The final failure of the wall exhibited a combination of sliding shear and diagonal tension as illustrated in Figure 9(b). The wall did not lose its stability and did not collapse at the end of the test, although the wall exhibited bed-joint sliding. Contrary to the control NRW, both edges of the wall remained intact. Local crushing of masonry (both bricks and mortar) took place in the vicinity of loading and supporting shoes. The main effect of the PP-band mesh was to restrain the separated masonry fragments for allowing the redistribution of the load within the masonry itself. The effect of both vertical and horizontal PP-bands could be expected as similar to the effect given by vertical and horizontal strips of bamboo mesh on masonry wall, but in a lower degree of quantity and quality of the effect of the bamboo strip mesh.

\section{Wall retrofitted with ferrocement belts}

The cracks propagated in a wider area of the wall [Figure 10(a)]. Failure of the wall RFB commenced as diagonal shear cracking in bed joint between the $7^{\text {th }}$ and $8^{\text {th }}$ brick 
course near the loading shoe just above the ferrocement overlay [Figure 10(a)]. No other signs of brick damage or tension failure of steel wire mesh were observed in the area covered by the upper ferrocement belt, except cracks developed over the ferrocement overlay and minor delamination at the vicinity of loading shoe and at the very bottom of the ferrocement belt. This claimed that ferrocement belts directly bear the stresses originated from the given external compressive and in-plane shear loads and dissipate and distribute the stress over the mesh. Compared with conventional reinforced concrete structures, ferrocement is reinforced in two directions; therefore, it may have homogeneous isotropic properties. Ferrocement generally has a high tensile strength and high modules of rupture because the specific surface of ferrocement is higher than that of reinforced concrete. Therefore, larger bond forces develop with the matrix resulting in higher number of cracks and smaller crack widths than those of conventional URM walls, conventional reinforced concrete and walls retrofitted with bamboo strip mesh and PP-band mesh.

Ferrocement belts also delayed crack initiation of the masonry wall. Initial cracking of the wall was followed by a sharp drop of the remaining strength capacity by $68.95 \%$ out of its utmost load of $44.6 \mathrm{kN}$, which was the highest post peak load recorded among all the test walls. After first crack initiation, the wall was able to regain the subsequent strength reductions very quickly (Figure 6). Compared to PP-band and bamboo strip meshes, ferrocement belts improve confining pressure of masonry walls leading to enhancement of the highest post peak load and tensile strength effectively. After the maximum post peak load, residual strength of the wall RFB decreased gradually as shown in Figure 6 until it completely lost the load carrying capacity (i.e., $0 \mathrm{kN}$ ) and stability.

Contradictory to the NRW, bricks in the $5^{\text {th }}$ brick course cracked and split open at a later stage of the testing period [Figure 9(d)], and local crushing occurred in the $5^{\text {th }}$ brick course (i.e., area without ferrocement belts). This is attributed to the ability of ferrocement belts to transfer shear stresses to the middle bricks from the top of the wall. Withal, crack width observed in the wall area without ferrocement belts was greater and crack propagation occurred more rapidly compared to the wall area with ferrocement belts. The reason for this phenomena is that the non-retrofitted wall area is acting as a conventional URM wall where the principal tensile stresses developed in the non-retrofitted wall area due to the combination of vertical and horizontal loads exceed the tensile strength of masonry leading to diagonal tension cracking through $4^{\text {th }}$ and $5^{\text {th }}$ brick courses along $4^{\text {th }}, 5^{\text {th }}$ and $6^{\text {th }}$ bed joints. It resulted in final failure of the wall with separation of wall into two segments and shear sliding (i.e., combination of stepped-joint and bed-joint sliding) of the upper part of the wall along $4^{\text {th }}$ and $5^{\text {th }}$ brick courses [Figure 10(b)].

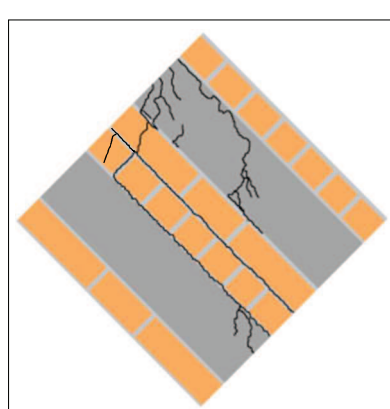

(a)

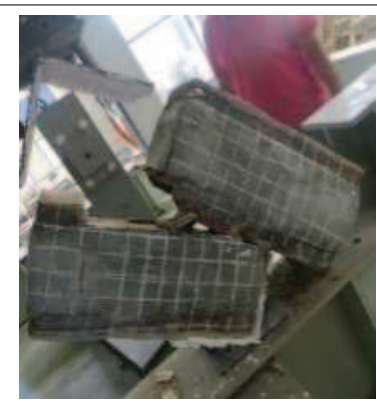

(b)
Figure 10: Specimens RFB: (a) crack formation; (b) specimen at the failure

However, separation of bricks within the separated two wall fragments with ferrocement belts could not be observed and both edges of horizontal diagonal of the wall remained unharmed. Other than minor cracks and delamination near the supporting edge, no other sign of distress or local crushing was observed in the area covered by lower seismic belts [Figure 10 (a) and (b)]. Interestingly, $1^{\text {st }}$ brick course and the nearby area remained intact.

\section{CONCLUSION}

The diagonal in-plane shear behaviour of traditional URM walls and URM walls retrofitted using bamboo strips, PP-bands and ferrocement belts was investigated. Parameters pertaining to seismic behaviour were determined, including maximum load bearing capacity, wall deformation, cracking pattern, and failure mode and degree of failure.

The test revealed that the traditional URM wall exhibited highly catastrophic shear slip failure along the mortar joints against static in-plane shear loads. Withal, it confirmed that the retrofitting is able to increase the static in-plane shear strength and deformation capacity of the masonry walls, significantly.

Although the wall with ferrocement belts possessed a significant maintenance of load after first crack initiation, increase of shear stress and deformation, and the highest post peak load, it separated along the mortar bed joints 
through non-retrofitted area in between the retrofitted areas and collapsed. Therefore, applying the ferrocement in belt pattern instead of covering the wall surface is ineffective for URM walls when considering the results of the static diagonal in-plane shear load test.

PP-band mesh and bamboo strip mesh can effectively improve the static in-plane load carrying capacity of masonry walls by increasing the diagonal resistance and deformation capacity, and may potentially be used to delay the catastrophic failure of URM structures under static in-plane shear loading.

Bamboo strip mesh method is the most effective method for retrofitting of URM walls against static inplane shear loads where it helps the wall to improve diagonal resistance, deformation capacity, shear stress and energy dissipation, and delay the catastrophic failure for a longer period. Further, the bamboo strip mesh possessed the minimum cost of retrofitting due to the high availability of bamboo in Sri Lanka. Bamboo can be easily grown in every climatic zone of Sri Lanka, whereas PP-bands must be imported. The use of bamboo for the purpose of retrofitting increases the seismic capacity of new and existing URM buildings as well as promote the local novel businesses in the vicinity.

\section{Acknowledgement}

The authors acknowledge the National Research Council for financial support under the research grant NRC 11-193 and the Department of Civil and Environmental Engineering, Faculty of Engineering, University of Ruhuna for technical assistance. The authors sincerely thank Prof. Hiroshi Mutsuyoshi, Department of Civil and Environmental Engineering, Saitama University, Japan for providing necessary experimental materials.

\section{REFERENCES}

Arya A.S. (2000). Non-engineered construction in developing countries - an approach towards earthquake risk prediction. Proceedings of the $12^{\text {th }}$ World Conference on Earthquake Engineering (WCEE), Auckland, New Zealand.

ASTM E519/ E519M (2010). Standard Test Method for Diagonal Tension (Shear) in Masonry Assemblages. American Society for Testing and Materials (ASTM) International, Pennsylvania, USA.
Bartolome A.S., Quiun D. \& Zegarra L. (2004). Effective system for seismic reinforcement of adobe houses. Proceedings of the $13^{\text {th }}$ World Conference on Earthquake Engineering, Vancouver, Canada.

Bartolome A.S., Quiun D. \& Zegarra L. (2008). Performance of reinforced adobe houses in Pisco, Peru earthquake. Proceedings of the $14^{\text {th }}$ World Conference on Earthquake Engineering, Beijing, China.

Blondet M., Garcia G.V. \& Brzev S. (2003). EarthquakeResistant Construction of Adobe Buildings: A Tutorial. (pdf). Available at http://www.world-housing.net/uploads/ WHETutorial Adobe English.pdf, Accessed 12 June 2012.

Dissanayake P.B.R. \& Mohadewan N. (2004). Potential earthquake risk on buildings in Sri Lanka. Proceedings of the Constructor, Sri Lanka B 1: 25-30.

Kodippili P. (2009). Country Profile 2009. Available at http:// www.adrc.asia/countryreport/LKA/2009/LKA2009.pdf, Accessed 23 August 2012.

Mendis W.S.W., De Silva G.S. \& De Silva G.H.M.J.S. (2014a). Dynamic in-plane behaviour of seismically strength un-reinforced masonry walls. Proceedings of the $5^{\text {th }}$ International Conference on Sustainable Built Environment (ICSBE-2014), Kandy, Sri Lanka.

Mendis W.S.W., De Silva Sudhira \& De Silva G.H.M.J. (2014b). Performance and retrofitting of unreinforced masonry buildings against natural disasters - a review study. ENGINEER, Journal of the Institution of Engineers, Sri Lanka XLVII(03): 71-82.

DOI: https://doi.org/10.4038/engineer.v47i3.6896

Munasinghe T. \& Curray J.R. (2013). Possible cause of recent earthquakes around Ampara, Sri Lanka: constrains from the earthquake distribution in the northeast Indian Ocean. Proceedings of $29^{\text {th }}$ Technical Sessions of Geological Society of Sri Lanka, pp. 1-3.

Sathiparan N., Pola M. \& Meguro K. (2008). Parametric study on diagonal shear and out of plane behaviour of masonry walletes retrofitted by pp-band mesh. The $14^{\text {th }}$ World Conference on Earthquake Engineering, Beijing, China.

Taghdi M., Bruneau M. \& Saatcioglu M. (2000a). Seismic retrofitting of low-rise masonry and concrete walls using steel strips. Journal of Structural Engineering 126(9): 1017-1025.

DOI: https://doi.org/10.1061/(ASCE)0733-9445(2000) 126:9(1017)

Taghdi M., Bruneau M. \& Saatcioglu M. (2000b). Analysis and design of low-rise masonry and concrete walls retrofitted using steel strips. Journal of Structural Engineering 126(9): 1026-1032.

DOI: https://doi.org/10.1061/(ASCE)0733-9445(2000) 126:9(1026)

Uduweriya S.B., Wijesundara K.K. \& Dissanayake P.B.R. (2013). Seismic risk in Colombo - probabilistic approach. SAITM Research Symposium on Engineering Advancements 2013 (SAITM - RSEA 2013), pp.124-128. 